\title{
MOBILE PORTAL IMPLEMENTATION STRATEGY: A THEORETICAL EXPLORATION
}

\author{
Ping Gao and Jan Damsgaard \\ Defortmant of Informatics, Copenhagen Business School
}

\begin{abstract}
Mobile portal plays an important role in mobile commerce market. Current literature focuses on static analysis on the value chain of mobile portals. This article provides a dynamic perspective on mobile portal strategy. Drawing upon network economics, we describe mobile portal implementation as a fourphase process. In different phase, a portal provider has various challenges to overcome and adopt diverse strategies, and correspondingly the regulator has different foci. The conceptual framework proposed in this article offers a basis for further analyses on the market dynamics of mobile commerce, and can be generalized to studying other networked technologies.
\end{abstract}

Key words: mobile commerce, mobile portal, network economics, strategy

\section{INTRODUCTION}

Technology advance begets a new business model called mobile commerce, which is an application potentially to bring wireless telecommunications and the Internet to the customers (Louis, 2001). It is expected that mobile commerce will be boomed by the deployment of $3 \mathrm{G}$ networks that enable a wideband, high-speed wireless access to Internet. Led by Japan, Korea and some European countries, the future of $3 \mathrm{G}$ market is 
about to unfold globally (Maitland et al., 2002). An academic analysis on mobile commerce implementation is of practical importance. As a new research field, deep theoretical studies on this topic are seldom found.

This paper reports the result of such a research. Particularly, as in the whole value chain of mobile commerce the mobile portal plays a key role $(\mathrm{Li}$ and Whalley, 2002), it will be our study focus. Current literature focuses on static analysis on the value chain of mobile portals (Kim and Kim, 2003; Sterling, 2002). Whilst such research efforts help us understand the positions of different mobile market actors in providing portal services, we lack a dynamic perspective on the strategy by a mobile portal provider. Drawing upon network economics, this article describes mobile portal development as a four-phase process. In different phase, the portal provider has various challenges to overcome and adopt diverse strategies, and correspondingly the regulator takes different measures to support the development of the mobile portal.

This paper proposes a conceptual framework for analyzing the strategies of mobile portal. It has five sections. The second section describes the characteristics of the mobile portals. The third section introduces the theoretical foundation. The fourth section is main body of analysis. Here we will answer two questions: in a specific stage of market and technological situation, what kind of an implementation strategy should the portal providers choose? What sort of a role should the regulator play? Finally, in the fifth section we conduct discussion and draw conclusions.

\section{MOBILE PORTAL}

A portal is commonly defined as a website that offers a set of services that helps users navigate the Internet. For Internet users it is a gateway to a variety of resources or data (Ward and Gardner, 2000). Mobile portal enables an extension of services from Internet to mobile devices. It presents contents that mobile phone users are able to access. Formed by aggregating applications (e-mail, instant messaging etc) and contents from various sources, a portal sets the business model of mobile commerce services (Kim and Kim, 2002). Mobile portal is not a replication of web on the mobile networks. Compared with a normal Internet portal, the mobile portal is characterized by supporting personalization and localization. Because mobile phones have small screens, mobile portals are particularly important for mobile commerce (Barnett et al., 2000).

In the value chain of mobile commerce, which is composed by venders, application developers, content providers, content aggregators, portal providers, network operators and service providers (Muller-Veerse, 2000), 
mobile portal providers play a specifically important role. In nature, mobile commerce is transactions with a monetary value that are conducted via mobile networks. As Muller-Veerse (2000) puts it, mobile commerce is all about applications and services on the mobile phones; it is about contents, rather than technological capability. Having direct contacts with customers and providing them a gateway to access the contents, a mobile portal gains a strategic importance in mobile commerce implementation. To fuel subscriber growth and hold customer loyalty, which is critical for generating more traffic revenue, network operators (e.g. DoCoMo and Sonera) have been keen to develop their mobile portals. Meanwhile, regarding mobile portals as an opportunity to reach customers at anytime and anywhere with personalized services which means high income, traditional web portals (Yahoo!, AOL etc) and many new independent content providers are active to have a share in mobile portal market (Sterling, 2002). The integration of Internet portal and mobile portal means the convergence of fixed and mobile market. Portal market is currently undergoing significant expansion, and the ownership and operation of portals is becoming an area of fierce competition. For users, mobile portals are the prime suppliers for web-based information that is delivered to their mobile terminals. There is an increased reliance on mobile portal by customers hence it is gaining importance (Barnett et al., 2000).

In theory, institution intermediary is assumed to play a key role in promoting technology implementation (King et al., 1994). In practice, a fair, efficient regulation has been necessary for telecommunications industry (Melody, 1999). Because the mobile network operator is capable to control access to portals hence it may hinder portal competition, in mobile commerce market the role of the regulators is specifically important in terms of securing a competition to protect the interests of customers and other portal providers (Maitland et al., 2002). Hence, while the strategy of portal providers is the major concern of this paper, the role of regulator in promoting mobile portal development will also be examined.

\section{THEORETICAL FOUNDATION}

According to Lyytinen and Damsgaard (2001), it is critical to consider the underlying specifies of the technology in order to decide the theoretical tool for analyzing its implementation. Mobile commerce is based on mobile access and Internet networks as standard technologies. Mobile portals must offer their customers the social interaction possibility hence will establish user community around services like dating services, gaming services etc (Sterling, 2002). Consequently network economics serves as an appropriate 
tool for our analytical purpose. Followings are major concepts to be drawn upon in our analysis.

\subsection{Lock-in effect}

In network economics, lock-in effects capture the fact that the use of certain technology or service becomes a habit that is hard to break (Shapiro and Varian, 1999). To operate a technology efficiently, a user needs to invest time and other resources so as to get acquainted with it. When a technology becomes well known to the user, she no longer pays attention to it or the dependency she has developed. Technology has become an extension of herself that is ready-at-hand. A clear example is the layout of the keyboard. We know where the different keys are located and we can operate the keyboard seamlessly in our endeavor to write. We do not need to know with what purposes the keys are ordered in the particular QWERTY way (David, 1985).

It is nuisance to change from something known well to something new and different. Network economics seeks to price this nuisance. In line with Shapiro and Varian (1999), a user that is locked into a standard technology or service must incur certain cost, if she wishes to switch to a new one. The magnitude of switch cost of a service decides the lock-in effects. The service providers must flexibly use lock-in strategies in their operations. On the one hand, they would create barriers that prevent the users from switching. On the other hand, in moving to new services, they must facilitate their incumbent customers to break the barriers set by traditional services.

\subsection{Network externality}

Shapiro and Varian (1999) identify the major sources of lock-in as the habit of using a technology and dependency to it. These lock-in effects are in an individual level, thus they omit switching costs related to a community of interacting agents that communicate with one another using the standard technology or service like online chat. In this case, a switch to a different service provider must incur cost for breaking relation with the community. Once a community has been locked in, the provider can "tax" its members. If the community is concentrated around one provider, this is specifically painful for a user. It should be the target of regulation to avoid the existence of market monopoly that may exert an over-taxation on the users.

The network externality emphasizes the value of a community to the service provider by its scale, and the costs of switch from the community for a user. The installed base of users is the most valuable asset of a provider (Markus, 1987). Community is an efficient way to create a critical mass of 
the installed base. How to make itself a community hub that may lock in customers to establish an installed base beyond a critical mass and take advantage of network externality, this is the strategic issue for a provider to survive. In providing telecommunications services, operators may promote network externalities by allowing interconnections between networks (Liebowitz and Margolis, 1999).

\subsection{Implementation of networked-technology}

According to Besen and Farrell (1994), when firms compete for user communities around some standard technologies, they use three combinations of strategies. In the first combination each company wants to set its own standard for a given technology and both are willing to fight for it. Besen and Farrell call this strategy as Tweedledum and Tweedledee. In the second combination, each company prefers its own standard technology but is willing to compromise rather than to go solo. This strategy is referred as the Battle of the sexes. Finally, there is the situation where one company prefers its own standard technology while the contestant, called as Pesky little brother, wishes to join the established network of technology users.

In studying the implementation of networked-technology, Damsgaard (2002) observes a fourth strategy. He defines it as Big brother as opposite to Pesky little brother. In the case of portal market, it denotes one portal has won the dominant position and does not want to share its community with the young contestants. These four types of strategies defined by Besen and Farrell (1994) and Damsgaard (2002) form the conceptual basis for us to examine the strategies of portal service providers, and the role of the regulator in the process of implementing mobile portals.

\section{A FRAMEWORK OF MOBILE PORTAL STRATEGY}

We argue to classify the whole process of implementing a mobile portal to attraction, contagion, entrenchment and defense phases. This four-stage model idealizes a successful implementation process from genesis to domination. Each stage poses a key challenge that must be overcome in order to proceed to the next one. If a challenge is not resolved properly, the mobile portal cannot evolve but will stagnate. The first three stages are transitional ones. In this time the "burn rate" of investment needs to be controlled (Lamont, 2001), and a safe transfer to the last stage should be realized within a reasonable period. In different phases, a mobile portal provider adopts various strategies as defined by Besen and Farrell (1994) 
and Damsgaard (2002), and the regulator has different concerns to promote mobile portal development. For simplification in this article we examine the market with only two portals. The analytical results are condensed in Table 1.

Table 1. Mobile portal implementation strategy

\begin{tabular}{|c|c|c|c|c|}
\hline & Attraction phase & $\begin{array}{l}\text { Contagion } \\
\text { phase }\end{array}$ & $\begin{array}{l}\text { Entrenchment } \\
\text { phase }\end{array}$ & Defense phase \\
\hline $\begin{array}{l}\text { Portal } \\
\text { provider }\end{array}$ & $\begin{array}{l}\text { Pesky little } \\
\text { brother } \\
\text { Attract users and } \\
\text { get them to } \\
\text { return. } \\
\text { Facilitating users } \\
\text { to switch from } \\
\text { normal Internet } \\
\text { portals and } 2 \mathrm{G} \\
\text { services. Follow } \\
\text { the incumbent in } \\
\text { service and } \\
\text { network standard }\end{array}$ & $\begin{array}{l}\text { Battle of the } \\
\text { sexes } \\
\text { Try to build up } \\
\text { user base } \\
\text { around different } \\
\text { services over } \\
\text { network. Extend } \\
\text { the user base } \\
\text { toward a critical } \\
\text { mass }\end{array}$ & $\begin{array}{l}\text { Tweedledum } \\
\text { and } \\
\text { Tweedledee } \\
\text { Build and } \\
\text { diffuse } \\
\text { proprietary } \\
\text { service that } \\
\text { may lead to a } \\
\text { dominance }\end{array}$ & $\begin{array}{l}\text { Big brother } \\
\text { Evolve with } \\
\text { backward } \\
\text { compatibility. } \\
\text { Keep } \\
\text { innovation in } \\
\text { services and } \\
\text { technology so } \\
\text { as to hold } \\
\text { customers }\end{array}$ \\
\hline Regulator & $\begin{array}{l}\text { Encourage a } \\
\text { common standard } \\
\text { in network. } \\
\text { Support an } \\
\text { operator to } \\
\text { develop its own } \\
\text { portal }\end{array}$ & $\begin{array}{l}\text { Enforce } \\
\text { interconnection, } \\
\text { interoperation } \\
\text { to adapt to } \\
\text { service } \\
\text { cooperation }\end{array}$ & $\begin{array}{l}\text { Monitor fair } \\
\text { competition } \\
\text { and equal } \\
\text { access to } \\
\text { networks from } \\
\text { all portals. } \\
\text { Adopt an } \\
\text { "arm's length" } \\
\text { policy }\end{array}$ & $\begin{array}{l}\text { Supervise fair } \\
\text { competition. } \\
\text { Beware over- } \\
\text { taxation }\end{array}$ \\
\hline
\end{tabular}

\subsection{Mobile portal provider}

Attraction phase. A mobile portal develops from the attraction phase. In this initial stage, the primary objective of a mobile portal provider is to attract users and let them try out its services. In the situation where there already exists an overlapping portal with a certain size of user base, the simplest strategy for the young provider is to imitate the established one in services in the hope to share the market that has been proven lucrative. The new portal can also provide services that the established one cannot offer, or add values to the incumbent's services to form its own products. Yet, to reduce users' cost of switching from the incumbent, in the method of using 
services an imitation to the established provider is necessary. The new provider can also take facility measures for example providing a help function for browsing its website. In the words of Besen and Farrell (1994), it will adopt a Pesky little brother strategy.

In this phase the lock-in degree of users to portals is generally low. The young portal will initiate the lock-in strategy by exploring a service that may set up its own user community, or share a community with the incumbent. At this stage the challenge for the new portal revolves around getting users interested in what it offers and making them want to return for more. Successful progression to the next stage depends on that there are enough users to continue using its services. For the established provider, the challenge from new services based on new technology should be its attention. For which it may also consider to initiate the Pesky little brother strategy in due time. But a backward compatibility must be guaranteed to let its customers to co-evolve alongside with it as innovation of service and technology proceeds.

As observed by Sterling (2002) a network operator and normal Internet portal are the most active providers of mobile portals. For an operator, if it has an installed base of $2 \mathrm{G}$ users it must make efforts to design its services to be backward compatible. In case this is infeasible in technology, a facilitating function should be provided to enable a smooth switch for the customer community. For a mobile portal developing from a normal Internet portal, the innovation should be based on current services so that the user base may go along with it to the mobile market. This is possible as users may like the services by Internet portal also be available via mobile devices (Kim and Kim, 2003).

Meanwhile, a network provider is also the owner of networks. The very first decision for it to make is the selection of network standard. The new operator may adopt a Pesky little brother strategy to follow the incumbent. This strategy favors network interconnection and service interoperation, which gives the new operator an opportunity of sharing a portal community with the incumbent. But in some cases this will invalid the smooth transfer in technologies from old standard to the new one, as what has happened in Japan. In this case, to bring their customer bases along, different operators may separately go for two standards (Pikula, 2001).

Content and portal market allows the existence of a lot of providers. In contrast, because of limitation of frequency resource and the need of a huge investment, the network market is restricted to competition within limited companies by the state based on a license system. At the beginning period there may be only one $3 \mathrm{G}$ operator in the market. Whilst cooperation with social portals will happen, in this time the operator may major rely on self to explore content and create its affiliated portal (Funk, 2001). This is efficient 
in time and necessary to avoid the risk of without profitable contents for the customers. Later on more providers will swarm in and form a competition with network operator in providing portals, and other competitive networks will also appear and join in mobile portal market.

Contagion phase. The contagion phase is a period of expending the user size. In this second phase of implementation, the focus of a mobile portal is to "infect" the recruited users so that they become carriers to help attract more users to join in. At this time the degree of lock-in of the user community to a provider is only moderate. Relatively the users can easily leave and participate in a rival. For a portal provider the successful progression to the next stage is dependent on achieving the critical mass (Markus, 1987). An existential crisis occurs if one portal cannot attract a sufficiently large number of users. In this stage while the users are not locked in yet and no provider has achieved a critical mass of users, there is no reason for them to engage in a battle, which is risky for both. Each provider is planning a good future and is paying attention to extend its user community, for which each one is willing to cooperate. The mobile portal providers will prefer an open-access between portals to a "walled-garden strategy (Barnett et al., 2000; Sterling, 2002). The open-access strategy creates value for end users, which may allow both portals to have more customers which may finally reach a critical mass. Hence Battle of the sexes is a proper strategy in the contagion phase.

In running the networks and providing portal services, the operators will abide by a Battle of the sexes strategy by promoting interconnection and interoperation, which is right out there in technology if a common standard is adopted in the attraction phase. For a user the major switching costs from a portal is being a member of a community around some services that allow active interactions among members, and the habits of using them (Shapiro and Varian, 1999). Because of interconnection, compared with services, the network creates a less significant switching cost. The switching cost from network is major due to the financial elements, i.e. the users need to pay an interconnection fee extra to the normal expense to get access to the community around previous operator, and bear a cost of opening a new account. Interconnection and interoperation allows social portals and customers a higher freedom of selecting network operators based on services. It is also good for an operator to diffuse services and extend network in terms that the customers will be not scared away for being locked-in to its network. Interconnection and interoperation encourages mobile commerce market to develop based on competition in portal services, and avoid the network market to move to a monopoly (Liebowitz and Margolis, 1999).

Entrenchment phase. The first two phases are periods of accumulating knowledge about market, and trying services so as to build up user 
community around some of them. Ideally in this entrenchment phase this work moves further to the step that a specific mobile portal has formed proprietary services of itself. By making the users adopt the proprietary services the community is locked in to a higher degree. If the portal fails in installing its proprietary services, its users will remain to have a high freedom to leave attracted by the competitive provider. This is the time to fight for the control of the community. When all firms choose to compete they decide to have a battle. Following Besen and Farrell (1994) they adopt a strategy of Tweedledum and Tweedledee. Every competitor attempts to win the dominant position by building a community around specific proprietary services that are able to lure over users from the rival's community and win over the "free" users. Moreover, the portal can use pricing strategy to dominate a niche of market. For example in Finland, because of low cost in investment, generally the service price of local mobile network operators is lower than that with cross-country networks; thus the market is differentiated between normal residents and these who need to travel frequently (Manninen, 2002).

Defense phase. The proprietary services will help a portal to dominate a niche market. Consequently the implementation of a mobile portal moves to the fourth phase of defending the market dominance. In the defense phase one has won the dominant position and does not want to share its community with the young contestants. In terms of Damsgaard (2002), the mobile portal adopts the strategy of Big Brother. Yet, facing technology innovation and the appearance of disruptive technologies, the dominance built around proprietary services is at the risk. Once a community is well established around a proprietary service there is an ongoing need to nurture it. What keep the community together are services, community features and switching costs. The community is not a static entity so at all times there are some users come and go as their natural contexts change. This is natural and will not affect the market structure in general. But if users are willing to leave for the competitor's services as perceived as more attractive the provider should be alert. The danger from disruptive technologies and services is real and it can bring giants down (Christensen, 1997). In this phase the challenge is to keep evolution going and incorporate new services and technologies, and avoid revolutions caused by disruptive ones. The idea is to move ahead while stay backward compatible (Shapiro and Varian, 1999).

\subsection{Regulator}

In general the governmental regulation should facilitate service competition by portals. Owing the networks, a network operator meanwhile 
as a portal provider has the advantage of establishing the dominance and jeopardizing a fair competition in portal service market. Hence the network owner should be the focal point of regulation (Melody, 1999). In principle, the regulator should foster the content as the "king" rather than allow the network owner to steer the market (Muller-Veerse, 2000). As a portal provider adopts different strategies by phases, the regulator should support its development by accordingly adjust its concentration as the implementation proceeds.

A common standard in networks facilitates interconnection and interoperation, which is to the benefit of customers as well as portals. A common standard may relieve the concern of the first mover that a future comer may surpass it through adopting a more advanced technology; hence it promotes the early investment on mobile commerce networks. This implies that in general the regulator should promote adopting a common standard in issuing network operating licenses. Yet, it must account the specific market situation that operators have already used different networks of last generation. For example in China, as two mobile operators respectively use GSM and CDMA systems, the regulator is considering to accordingly issue WCDMA and CDMA2000 licenses to them so that their networks can economically upgrade from the second to the third generation (Lamont, 2001; Zhang and Prybutok, 2005).

Moreover, the regulator should support the operator to build its affiliated portal. This is necessary to encourage the operator to invest on mobile commerce without the concern of content unavailability, hence is an efficient measure to nurture the mobile commerce market to develop.

In the contagion phase, the market is characterized by cooperation between competitors. While interconnection and interoperation might have been primarily promised in technology by adopting a common standard in last phase, at this phase the regulator must guarantee its practical enforcement. Though market force should play main role in normalizing the market structure, fair and efficient regulation is necessary in cases for example when two portals cannot reach an agreement over interconnection fees.

In the third phase the competitors fight for the user community. The focus of regulation is to guarantee a fair competition between the portals affiliated to an operator and these without networks. Ideally the portal services and network operation of a network operator are kept an "arm's length". It is advised to prohibit cross subsidies for example from voice communications to mobile commerce services. Network operators must allow their networks to be accessible to all portals at reasonable prices, including that of competitive operators. In fact, this will generate more traffic sources for network operators hence is also to their benefit, as is 
demonstrated by DoCoMo and Telia (Muller-Veerse, 2000). The operators have a privilege of controlling the portals that are pre-set on a SIM card when it is distributed. For a customer to access contents of network operator's own portal and that of other providers', the operator should be not allowed to set difference in convenience and efficiency, and discrimination in price. In short, the regulator should guarantee that the networks are neutral platforms for competition in providing mobile commerce.

The defense phase sees a differentiated market that has locked in customers around different services to a high degree. While still keeping an eye on fair competition, the regulator needs to warrant that over-taxation on locked-in customers would not happen.

\section{DISCUSSION AND CONCLUSION}

Drawing upon network economics, we have theorized the strategy of portal providers, and the role of a regulator in implementing mobile portals. We argue a portal provider must overcome four existential crises. First, if visitors do not return to its services it cannot evolve. Second, if a critical mass of users cannot be reached, implementation will stagnate. Third, if proprietary services cannot be established to lock in the customers, the user community remains open for competitors to poach. Finally, whenever new innovations occur, they must incorporate them into their services to avoid a situation where users will have to leave so as to use new services.

The role of regulation should be to prevent a network operator to take advantage of its network to dominate the service market. In the whole process of implementing mobile services, the focus of a regulator evolves by phases to adapt to the different strategy of portal providers. At the beginning, the regulator should encourage a single network standard in issuing licenses, and promote investment on networks by allowing the operators to build their own portals. In the second phase, the focus is to guarantee interconnection and interoperation, and promote the Battle of the sexes strategy of portal providers. In the third phase, to adapt to the Tweedledum and Tweedledee strategy of the portals, the regulator should facilitate service competition by warranting that a network allows an equal access by its affiliated portal and the independent ones, and encouraging the subscribers of a network to access other portals. In the final phase, its major task is to prevent an overtaxation to happen.

An "all or nothing" characteristic of interactive technology implementation has been noticed in literature (Markus, 1987). Similarly, the competition will make the portal market to become tippy. Some providers may leave the market without reaching the fourth phase of life cycle, while 
few dominant others stay to share the market. Moreover, because a portal can provide many different services, the failure in some mobile commerce services does not mean its collapse. The market can be differentiated by services.

At present the critical problem of mobile commerce development is to start 3G networks. Then the Pesky little brother strategy may lead to a "penguin phenomenon", which describes a swarm of penguins walk around the beach and hesitate to jump into the sea; but as a leader appears the rest will follow. At the start the power is on the side of network operators, as without a network the services cannot be realized hence no one will establish the mobile portal. Operators are in a critical position to form an "ecosystem" which is the cooperation within the provider community to create profitable mobile commerce models (Costello, 2002). The first mover is potentially to have advantage, but is also adventurous in that a huge investment in network can be repaid only by good services. Hence an operator should be encouraged to explore contents and portal services. The good start of network operators will lead content market to develop, which in turn may bring mobile commerce market to soar (Sterling, 2002).

This study is theoretically exploratory by nature. We move one step towards forming a conceptual framework that dynamically describes mobile portal implementation. The conceptual framework proposed offers a basis for further analyses on the market dynamics of mobile commerce. It can be generalized to studying other networked technologies that allow the establishment of a user community.

We have only considered a simplified market with only two competitors. As mobile market is becoming complex in terms of services, technologies, and participants of market and the relationship among them, in future study the influence of broad market elements on portal strategy should be put into consideration ( $\mathrm{Li}$ and Whalley, 2002). It is a research opportunity of incorporating present literature of mobile portal value chain with our framework. Moreover empirical work is needed to validate our arguments.

\section{REFERENCES}

Barnett N., Hodges, S., Wilshire, M.J. "M-Commerce: An Operator's Manual", The McKinsey Quarterly, (37:3), 2000, pp.163-173.

Besen, S.M., Farrell, F. "Choosing How to Compete: Strategies and Tactics in Standardization", Journal of Economic Perspectives, (8:2), 1994, pp. 117-131.

Christensen, C.M. The Innovator's Dilemma: When New Technologies Cause Great Firms to Fail, Harvard Business School Press, 1997.

Costello, J. Partnering: The Essential $3 G$ Challenge. Ernest \& Young Report. Available at http://www.cgey.com/tmn/nmi/3g/downloads/3g_partners.pdf, 2002.

Damsgaard, J. "Managing An Internet Portal", Communications of AIS, (9), 2002, pp.408-420 
David, P.A. "Clio and the Economics of QWERTY", The American Economic Review, (75:2), 1985, pp.332-337

Funk, J.L. The Mobile Internet: How Japan Dialed Up and the West Disconnected, ISI Publications, 2001.

Kim, G., Kim, K. "Two-way Convergence of the Korean Portal Market: Competitive Responses to the New Mobile Internet Technology", Proceedings of Second International Conference on Mobile Business, 2003, pp. 261-270.

King, J.L., Gurbaxani, V., Kraemer, K.L., McFarlan, F.W., Raman, K.S. Yap, C.S. "Institutional Factors in Information Technology Innovation", Information Systems Research, (5:2), 1994, pp. 139-169.

Lamont, D. Conquering the Wireless World: The Age of M-Commerce, Capstone, 2001

$\mathrm{Li}, \mathrm{F}$., Whalley, J. "Deconstruction of the Telecommunications Industry: from Value Chains to Value Networks", Telecommunications Policy, (26), 2002, pp. 451-472.

Liebowitz, S.J., Margolis, S.E. Winners, Losers \& Microsoft: Competition and Antitrust in High Technology, The Independent Institute, Okaland, CA, 1999.

Louis, P. J. M-Commerce Crash Course: The Technology and Business of Next Generation Internet Services, McGraw-Hill, 2001.

Lyytinen, K., Damsgaard,J. "What's Wrong with the Diffusion of Innovation Theory". In Diffusing Software Product and Process Innovations, M.A. Ardis and B.L. Marcolin Ed., 2001, pp. 173-190. Kluwer Academic Publishers.

Maitland, C.F., Bauer, J.M., Westerveld, R. "The European Market for Mobile Data", Telecommunications Policy, (26), 2002, pp. 485-504.

Manninen A. Standardization of $2 G$ Mobile Communications. Unpublished Dissertation. Faculty of Information Technology, University of Jyväskylä, Finland, 2002.

Markus, M.L. "Towards a Critical Mass Theory of Interactive Media: Universal Access, Interdependence and Diffusion", Communications Research, (14:5), 1987, pp. 491-511.

Melody, W.H. "Telecom Reform: Progress and Prospects", Telecommunications Policy, (23:1), 1999, pp. 7-34.

Muller-Veerse, F. Mobile Commerce Report, Durlacher Research Ltd, London, 2000.

Pikula, V. Mobile Internet Services in Japan: Identifying Industrial Organization as a Key Factor for Success, Master degree thesis, Erasmus University Rotterdam, 2001.

Shapiro, C., Varian, H.R. Information Rules: A Strategic Guide to the Network Economy, Harvard Business School Press

Sterling, D. Mobile Portal Strategy: When Did Business Partnerships Become So Critical to Customer Value? IBM Institute for Business Value Report, Available at http://www1.ibm.com/services/files/ibv_mobileportal.pdf, 2002

Ward, H.J., Gardner, M. "Portals: Their Role in the Emerging Networked Economy", Journal of the Institution of British Telecommunications Engineers, (1:4), 2000, pp.14-21.

Zhang, X., Prybutok, V.R. "How the Mobile Communication Markets Differ in China, the U.S., and Europe", Communications of the ACM, (48:3), 2005, pp.111-114. 